\title{
Case Report \\ Ovarian cystic teratoma with a dysgerminoma component in a child
}

Ravibindu Ranawaka1, Sandini Gunarathne', Mahendra Somatilake

${ }^{1}$ Lady Ridgeway Hospital for Children, Colombo, Sri Lanka,

Keywords: mature cystic teratoma of ovary in children, malignant transformation of cystic teratoma of ovary, dysgerminoma

Corresponding Author: Ravibindu Ranawaka < rravibindu@yahoo.com>(iD) http://orcid.org/0000-0001-9150-7904

Received: August 2017, Accepted September 2017, Published: October 2017

Competing Interests: Authors have declared that no competing interests exist

This is an open-access article distributed under a Creative Commons Attribution-Share Alike 4.0

International License (CC BY-SA 4.0), which permits unrestricted use, distribution, and reproduction in any

medium, provided the original author and source are attributed and materials are shared under the

same license.

\section{Introduction}

Mature cystic teratoma of ovary (MCTO) is a common tumour among young adult females accounting for around $20 \%$ of all ovarian tumours [1, 2]. It is relatively rare in children below 12 years of age. There is about $1 \%$ risk of MCTO transforming to malignancy: most frequently into squamous cell carcinoma [1]. We did not find any case reports on transformation of MCTO into dysgerminoma in children.

We report a six-year-old girl who presented with a cystic ovarian tumour which was found to be a cystic teratoma with a malignant dysgerminoma component. Management was further complicated due to issues regarding compliance.

\section{Case Presentation}

A six-year-old healthy girl was incidentally found to have a right adnexal mass measuring $5.5 \mathrm{~cm} \times 3.2 \mathrm{~cm}$ on ultrasound scan of the abdomen. Repeat ultrasound scan after two weeks, identified a multi-cystic mass with thick septae having the dimensions of $6.3 \mathrm{~cm} \times 4.8 \mathrm{~cm} \times 5.9 \mathrm{~cm}$. The right ovary was not identified separately. The left ovary measured $2.3 \mathrm{~cm} \times 1.6 \mathrm{~cm}$. Uterus and other abdominal viscera were normal. The ultrasonographic findings were compatible with an ovarian dermoid cyst.

Surgical excision was discussed but her social circumstances led to a delay of two months. At this time, she experienced mild lower abdominal discomfort. Ultrasound scan revealed that the mass had enlarged to $8.2 \mathrm{~cm} \times 6 \mathrm{~cm} \times 5.7 \mathrm{~cm}$. Rest of the abdominal viscera was sonographically normal. Pre-operative full blood count, serum electrolytes, renal profile and chest x-ray were normal. Tumour markers; alpha fetoprotein and beta HCG levels were within normal range.

At laparotomy, through a standard right hemi-Pfannenstiel incision [3], a $13 \mathrm{~cm} \times 10 \mathrm{~cm}$ size cystic right ovarian mass was excised (Figure 1). There was no salvageable right ovarian tissue. The left ovary, uterus and pelvic viscera appeared normal. No regional or 
para-aortic lymphadenopathy was identified. The clinical impression was that of a benign cystic teratoma. She made an uneventful recovery following surgery.

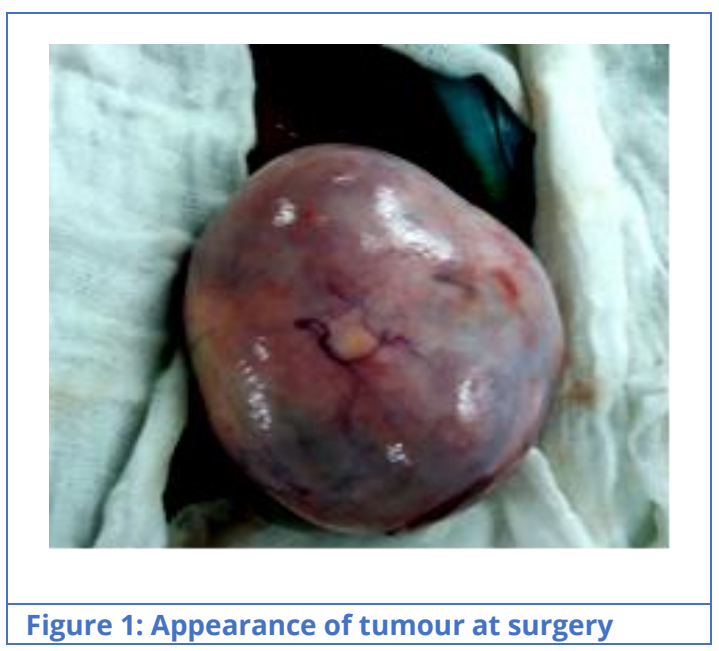

The lobulated mass with a thick fibrous capsule was found to be a cystic tumour on sectioning. Microscopy identified skin appendages and sebaceous cysts, cartilage, smooth muscle, lymphoid follicles and intestinal epithelium consistent with a "mature cystic teratoma" (Figure 2).

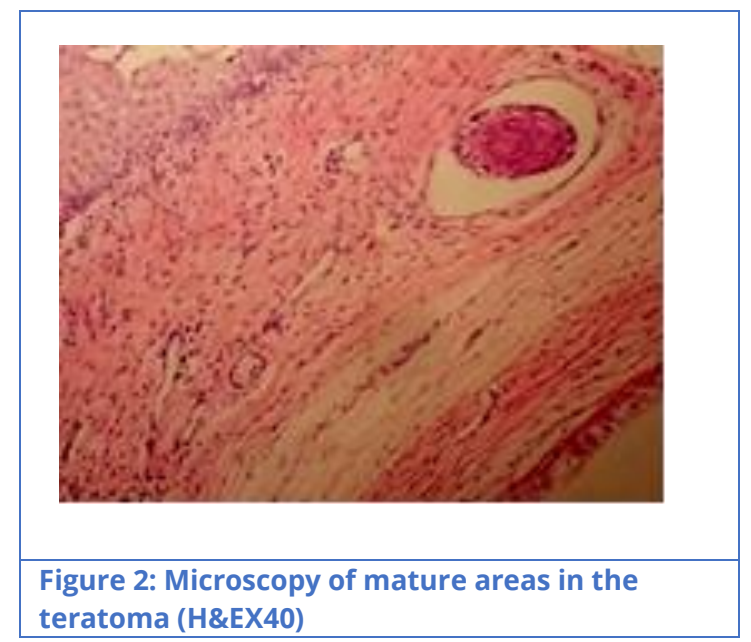

Interestingly, an area of malignant dysgerminoma, approximately $10 \mathrm{~mm}$ in size, was identified within the tumour. It had irregular sheets of germ cells with prominent vesicular nuclei and eosinophilic cytoplasm surrounded by lymphocytic infiltration. There was brisk mitotic activity and atypical mitosis. Immature areas were not seen (Figure 3a). Immunohistochemistry with CD117 and PLAP confirmed the diagnosis of a malignant dysgerminoma component (Figure 3b). 


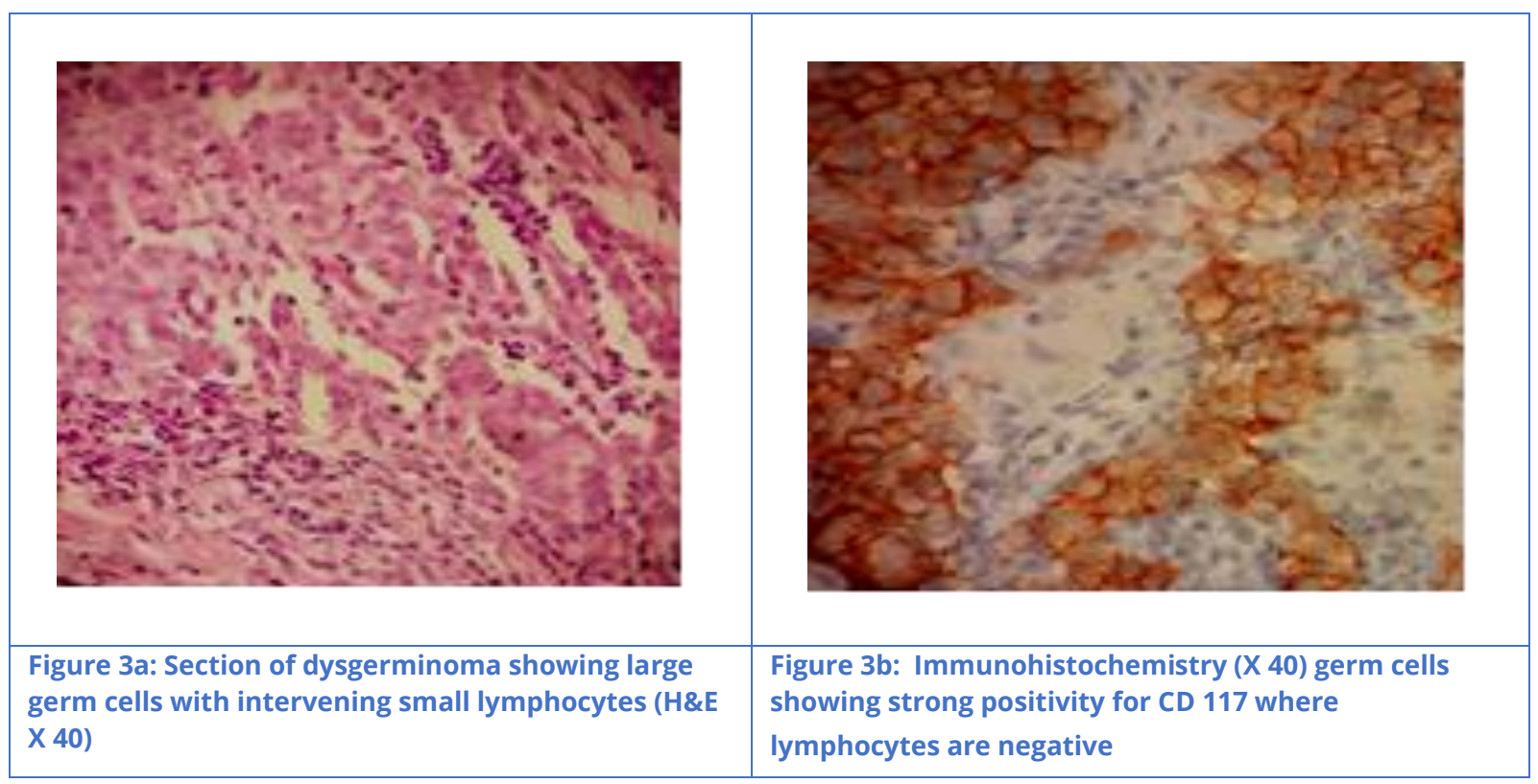

The final diagnosis was, predominance of mature teratoma elements and $10 \mathrm{~mm}$ area of dysgerminoma in the completely excised tumour. The tumour was classified under ICDO coding 9084/3; teratoma with malignant transformation [4].

In view of the dysgerminoma component, she underwent two courses of chemotherapy with carboplatin, bleomycin and etoposide as per Children's Cancer and Leukaemia Group-Germ Cell Group-protocol [5]. Post-operative tumour marker levels were normal. She remains well after completion of treatment.

\section{Discussion}

Identification of a coexisting dysgerminoma component, in an apparently mature cystic teratoma of the ovary, opened up a new dimension to the management $[1,4,5]$. Complete surgical excision is curative for mature cystic teratoma of the ovary. Management of the dysgerminoma component, after complete excision, was debatable: chemotherapy versus surveillance for tumour recurrence. Surveillance includes regular monitoring of tumour marker levels. Compliance with regular screening using tumour marker assays at standard intervals would be crucial if the post-operative chemotherapy was to be avoided.

This child had normal pre-operative tumour marker levels and the tumour had been completely excised. Two courses of chemotherapy offer complete cure and eliminates the need for regular screening as per Children's Cancer \& Leukaemia Group-Germ Cell Group-protocol [5].

With the intention of a "complete cure", after having considered her negative initial tumour marker levels and the possibility of poor compliance during follow up, two cycles of chemotherapy was given.

Management of tumours with complex histology in children becomes challenging when issues on compliance are encountered. In these circumstances, a multidisciplinary team approach would enable improved patient outcome. 


\section{References}

1. Talerman A, Vang R. Germ cell tumors of the ovary. In Blaustein's pathology of the female genital tract 2011 (pp. 847-907). Springer US. https://doi.org/10.1007/978-14419-0489-8_16

2. Goudeli C, Varytimiadi A, Koufopoulos N, Syrios J, Terzakis E. An ovarian mature cystic teratoma evolving in squamous cell carcinoma: A case report and review of the literature. Gynecologic oncology reports. 2017 Feb 28; 19:27-30. https://doi.org/10.1016/j.gore.2016.12.005

3. Setchell ME. Gynaecological Surgery; Kirk RM, editor. General surgical operations. Churchil Livignston; 2000; 842-843. ISBN: 0443063966

4. Nogales F, Talerman A, Kubik-Huch RA, Tavassoli FA, Devouassoux-Shisheboran M. Germ cell tumours. World Health Organization Classification of Tumours: Pathology and Genetics of Tumours of the Breast and Female Genital Organs. 2003; 1:168-73. https://www.iarc.fr/en/publications/pdfs-online/pat-gen/bb4/BB4.pdf (Accessed 11th September 2017)

5. Children's Cancer \& Leukaemia Group Germ Cell Group: Interim guidelines for the treatment of extracranial germ cell tumours in children and adolescents. January 2011. http://www.bspho.be/wp-content/uploads/CCLG-guidelinesextracranial-germcell-tumor.pdf (Accessed $11^{\text {th }}$ September 2017) 